\title{
Assessment of Rumen Mucosa, Lung, and Liver Lesions at Slaughter as Benchmarking Tool for the Improvement of Finishing Beef Cattle Health and Welfare
}

\author{
Luisa Magrin, Marta Brscic, Isabella Lora, Paola Prevedello, Barbara Contiero, \\ Giulio Cozzi* and Flaviana Gottardo
}

Department of Animal Medicine, Production and Health, University of Padova, Padova, Italy

\section{OPEN ACCESS}

Edited by:

Edward Narayan,

The University of

Queensland, Australia

Reviewed by:

Rachel Allavena,

The University of

Queensland, Australia

Julia Adriana Calderon Diaz,

Moorepark Animal and Grassland

Research Centre, Teagasc, Ireland

*Correspondence:

Giulio Cozzi

giulio.cozzi@unipd.it

Specialty section:

This article was submitted to

Animal Behavior and Welfare,

a section of the journal

Frontiers in Veterinary Science

Received: 29 October 2020 Accepted: 07 December 2020

Published: 15 January 2021

Citation:

Magrin L, Brscic M, Lora I, Prevedello P, Contiero B, Cozzi G and Gottardo F (2021) Assessment of

Rumen Mucosa, Lung, and Liver Lesions at Slaughter as Benchmarking

Tool for the Improvement of Finishing Beef Cattle Health and Welfare.

Front. Vet. Sci. 7:622837. doi: $10.3389 /$ fvets.2020.622837
Abattoir post-mortem inspections offer a useful tool for animal disease surveillance. The present cross-sectional study aimed at assessing the prevalence of rumen mucosa, lung, and liver lesions in 153 randomly selected batches of finishing beef cattle through a post-mortem inspection at the abattoir. At least 15 animals per batch were inspected at slaughter by two veterinarians for a total of 2,161 animals (1,376 bulls; 785 heifers) coming from 80 Italian commercial farms. Rumens were inspected by recording as binary variables (presence/absence) signs of hyperkeratosis, ruminitis, ulcer, and star scars. Similarly, lungs were inspected for signs of pneumonia and livers for signs of lipidosis, abscesses, and/or adherence. Hyperkeratosis of the mucosa and signs of ruminitis were detected in 58 and $30 \%$ of the inspected rumens, respectively. Ruminal star scars were more prevalent in bulls than in heifers (18 vs. $11 \% ; P<0.05)$. Signs of severe pneumonia were observed in 10\% of the lungs; abscess and/or adherence in $4 \%$ of the livers. Hyperkeratosis of rumen mucosa was correlated to signs of ruminitis, and signs of ruminitis were correlated to star scars. No correlations were found between hepatic lesions and any other rumen or lung disorders. The wide variability observed among batches for the prevalence of specific lesions suggested the development of a benchmarking system to provide feedback to the farm veterinarians, as these lesions can be reflective of a subclinical disease status not easy to be detected in the live animal. Quartiles of the batch prevalence of rumen, lung, and liver alterations (if $\geq 1 \%$ ) were calculated as a benchmarking tool, and third quartile value was proposed as an alarm threshold for each lesion. The use of the benchmarking system could allow to allocate each inspected batch to a specific "health class." Critical batches with a prevalence above the alarm threshold for a given lesion should be reported to veterinarians of the origin farms where actions should be taken in order to identify and lower the risk factors for that specific health issue. Knowledge of post-mortem inspection data along with the implementation of the proposed benchmarking system should help farm veterinarians to improve herd management from a health and welfare perspective.

Keywords: beef cattle, intensive production system, rumen hyperkeratosis, star scar, pneumonia, liver disease, post-mortem inspection, benchmarking system 


\section{INTRODUCTION}

Post-mortem assessments at slaughter in cattle (1, 2), pigs (3), and poultry (4) have been recently considered a useful tool for animal disease surveillance. Inspections at slaughter offer the advantages of monitoring a large number of animals from several batches on the same day and collecting data from different organs in a reasonable time. This type of evaluation appears particularly cost- and labor-effective for the assessment of several digestive disorders or multiorgan diseases that could remain partially undetected in vivo. As in the intensive beef production systems, the appearance of feeding and management disorders could have a poor clinical manifestation (5), and the outcomes of the inspection could indirectly reveal some critical aspects of the animals' management in their farm of origin. For instance, respiratory diseases that are the most commonly reported health and economic problem both in feedlots and in intensively finishing beef cattle units (6-8) are often undetected at subclinical level or underdiagnosed on farm (9). Recently, the evaluation of the signs of bovine respiratory disease at slaughter has been proposed as an effective tool to define their negative impact during the fattening cycle $(8,10)$.

With regard to digestive disorders, subacute rumen acidosis (SARA) is considered an important issue for both beef cattle health and farm economy $(11,12)$. The development of SARA has been associated with the provision of high amounts of dietary non-structural carbohydrates (13) and/or of an insufficient amount of structured fiber (14). Recent findings in dairy cattle suggested that SARA is associated with a compromised rumen barrier and hindgut epithelium function that might allow toxin translocation and bacteria migration into the bloodstream, promoting local and systemic inflammation $(15,16)$. However, SARA diagnosis on beef farms is still challenging, since it is not associated with specific clinical signs (17). Ruminocentesis and rumen fluid analysis are direct diagnostic tools for SARA (18), but they are invasive and labor- and time-consuming, thus limiting the number of cattle that can be diagnosed. As an alternative to the direct on-farm diagnosis, post-mortem evaluation at slaughter of gross pathological evidence of rumen mucosa damage and specific liver alterations could be a retrospective strategy for the monitoring of beef cattle health, without any invasive handling on live animals.

Based on a post-mortem data collection at the abattoir from a wide range of randomly selected beef cattle batches coming from several fattening units, the present study aimed at (1) assessing the prevalence of different rumen mucosa, lung, and liver lesions; (2) calculating the potential correlations among different alterations detected on the same organ and among alterations detected on different organs; (3) developing a benchmarking system based on the prevalence of the recorded damage to drive cattle health improvements by farm veterinarians.

\section{MATERIALS AND METHODS}

A cross-sectional study was set up to gather information about the prevalence of rumen mucosa, lung, and liver alterations in finishing beef cattle at the slaughterhouse through a post-mortem inspection. Data collection was carried out in three commercial cattle slaughterhouses located in Northern Italy from April 2016 until March 2017. Post-mortem evaluations were carried out during 30 observation days on batches of cattle that were regularly slaughtered according to the ordinary slaughterhouse planning. Each observation day lasted from 06:00 h until 13:00 $\mathrm{h}$ with a target of inspecting at least six batches per day. A batch was considered a group of finished beef cattle of the same breed [Charolaise $(\mathrm{CH})$, Limousine (LIM), or crossbreds (CR)] and category (bulls or heifers) coming from the same farm and belonging to the same slaughter group (same loading, transportation, unloading, lairage time, and slaughtering process). All farms of origin were located in the Po Valley (Italy), and their distance from the slaughterhouses was $<3 \mathrm{~h}$. A priori, it was set to inspect the organs of at least the first 15 animals per batch for batches larger than 15 animals, and of all the animals in case of smaller batches. This approach was used to trace the organs (rumen, lungs, and liver) of the same animal by two trained veterinarians located in different areas of the slaughterhouse (dispatch and tripery). The set of measures used for the study are described below and further detailed in Table 1. They have been chosen for their quick applicability (about $1 \mathrm{~min} /$ organ) without interfering with the regular working schedule of the slaughter line.

\section{Organ Inspection}

Rumens were inspected in the tripery after their dissection from intestines, omasa, and abomasa and their opening and emptying by the slaughterhouse operators. One trained veterinarian assessed rumen mucosa directly at the slaughter line having a water pump available to rinse the organ. Macroscopic alterations such as hyperkeratosis (Supplementary Figure 1), signs of ruminitis (Supplementary Figure 2), ulcers, and star scars (Supplementary Figure 3) were registered as binary measures (present/absent) following the methods adopted by previous studies and detailed in Table 1. Whenever there was presence of rumen parasites (Paramphistomum), it was also recorded as binary (presence/absence).

Using a simplified version of the assessment method described by previous researchers (Table 1), a second trained veterinarian examined lungs and livers directly in the slaughter line in the dispatch area. The assessor was positioned between the operator who detached the pluck from the carcass and the official veterinary inspector in order to visually and tactually inspect the organs before the official veterinarian did any cut or seizure. The assessor evaluated both lungs and attributed a score to the signs of pneumonia according to the description reported in Table 1 and Supplementary Figure 4 recording the worst condition of both lungs.

At the liver level, signs of lipidosis and the presence of abscesses and/or adherences were recorded as binary according to the criteria adapted from previous studies and reported in Table 1. 
TABLE 1 | The scoring system used for rumen, lung, and liver evaluation at slaughter in beef cattle.

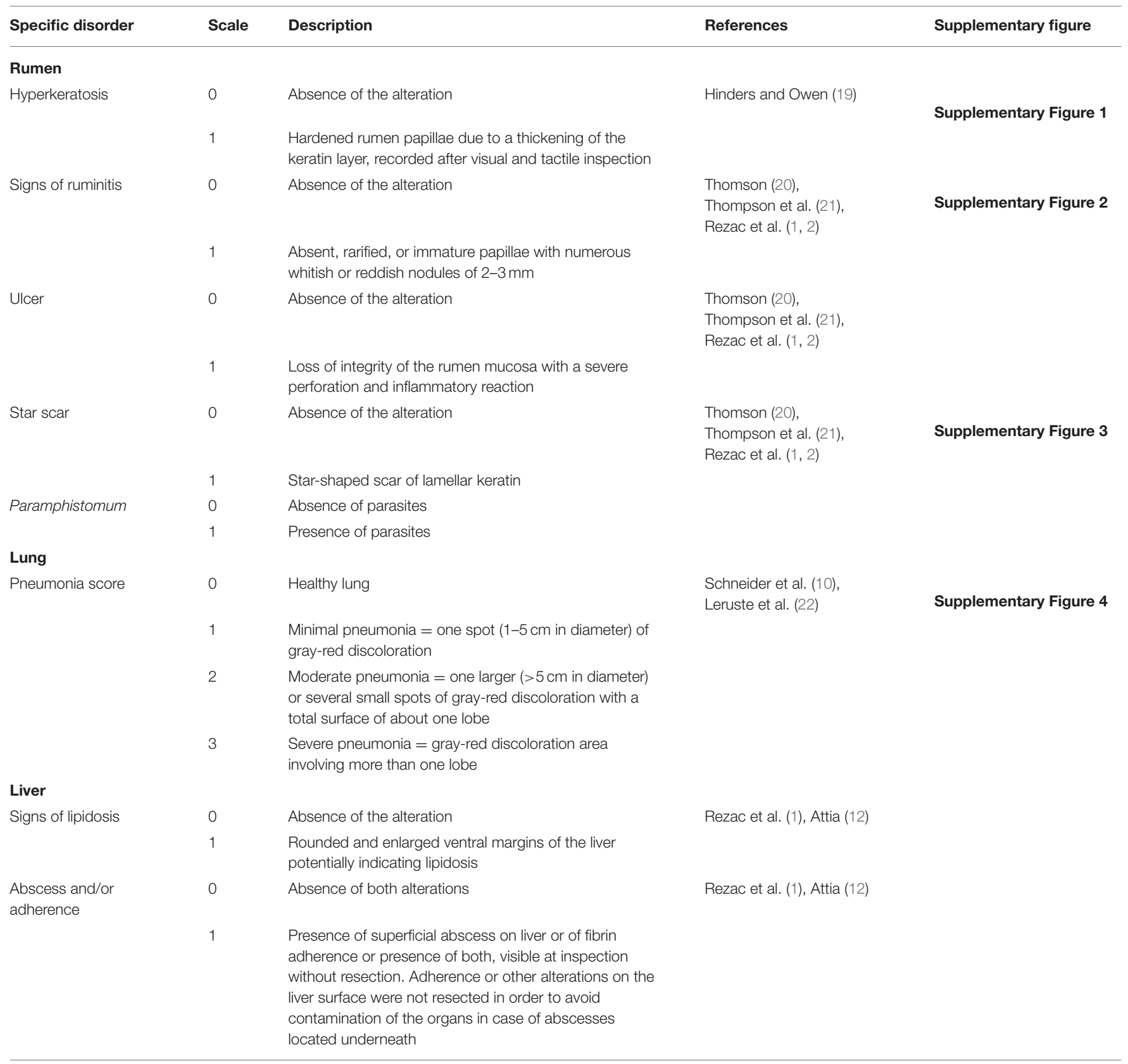

\section{Statistical Methods}

The statistical analyses were carried out using SAS (9.3; Institute Inc., Cary, NC) and XLSTAT (Addinsoft, New York, NY). For binary variables, score 0 was used for the absence and score 1 for the presence of alteration. Batch was the experimental unit for all the prevalence of rumen, lung, and liver alterations. Per batch, the prevalence of rumen, lung, and liver alterations was calculated as the ratio of the number of organs with a specific score over the total number of organs inspected and expressed as a percentage. Normal distribution of the batch prevalence of all alterations was tested using the Shapiro-Wilk test.
When the batch prevalence for a given lesion resulted $\geq 1 \%$, it was tested for the association with breed and gender. In particular, the prevalence of normally distributed data regarding lesions such as rumen hyperkeratosis, signs of ruminitis, and Paramphistomum, and lungs with minimal (Score 1) and moderate pneumonia (Score 2) were analyzed using a mixed model that considered breed, gender, and their interaction as fixed effects, and farm as random effect, with the Bonferroni adjustment option. Mann-Whitney test was performed to analyze the effect of gender, and Kruskal-Wallis test was used to analyze the effects of breed and gender $\times$ breed interaction for 
TABLE 2 | Effects of breed, gender, and their interaction on the prevalence of specific organ lesions recorded post-mortem at the slaughterhouse in 153 batches of finishing beef cattle coming from 80 Italian commercial farms.

\begin{tabular}{|c|c|c|c|c|c|c|c|c|c|}
\hline \multirow[t]{2}{*}{ Specific disorder } & \multirow[t]{2}{*}{ Overall $^{1}$} & \multicolumn{3}{|c|}{ Breed (B) } & \multicolumn{2}{|c|}{ Gender (G) } & \multicolumn{3}{|c|}{ Significance } \\
\hline & & $\mathrm{CH}$ & LIM & Other & Bull & Heifer & B & $\mathbf{G}$ & $\mathbf{B} \times \mathbf{G}$ \\
\hline \multicolumn{10}{|l|}{ Rumen mucosa } \\
\hline Hyperkeratosis ${ }^{2}$ & 57.5 & $53.1 \pm 3.0$ & $58.5 \pm 5.2$ & $61.6 \pm 4.3$ & $58.9 \pm 3.1$ & $56.6 \pm 4.0$ & ns & ns & ns \\
\hline Signs of ruminitis ${ }^{2}$ & 29.9 & $25.9 \pm 2.6$ & $29.4 \pm 4.8$ & $35.6 \pm 4.1$ & $32.8 \pm 2.7$ & $27.9 \pm 3.7$ & ns & ns & ns \\
\hline Ulcer & 0.4 & & & & & & & & \\
\hline Star scar ${ }^{3}$ & 14.9 & $15.0(11.1-18.8)$ & $12.0(7.9-16.1)$ & 18.4 (10.9-25.9) & $17.5^{\mathrm{a}}(13.7-21.3)$ & $11.4^{\mathrm{b}}(6.9-15.9)$ & ns & * & ns \\
\hline \multicolumn{10}{|l|}{ Lung } \\
\hline Minimal pneumonia ${ }^{2}$ & 19.8 & $17.6 \pm 1.4$ & $21.7 \pm 2.6$ & $22.5 \pm 2.3$ & $21.9 \pm 1.5$ & $19.4 \pm 2.1$ & ns & ns & ns \\
\hline Moderate pneumonia² & 9.3 & $9.3 \pm 1.1$ & $6.4 \pm 1.9$ & $11.1 \pm 1.6$ & $8.7 \pm 1.1$ & $9.2 \pm 1.4$ & ns & ns & ns \\
\hline Severe pneumonia ${ }^{3}$ & 10.3 & $9.7(6.9-12.5)$ & 12.7 (7.5-17.9) & $10.2(6.3-14.1)$ & $10.6(7.7-13.5)$ & $9.9(7.2-12.6)$ & ns & ns & $\mathrm{ns}$ \\
\hline \multicolumn{10}{|l|}{ Liver } \\
\hline Signs of lipidosis & 0.1 & & & & & & & & \\
\hline Abscess and/or adherence ${ }^{3}$ & 3.8 & $4.1(2.8-5.4)$ & $4.4(2.3-6.4)$ & $2.8(1.1-4.5)$ & $4.3(3.1-5.6)$ & $3.0(1.6-4.4)$ & ns & ns & ns \\
\hline
\end{tabular}

${ }^{1}$ Only disorders having an overall prevalence $>1 \%$ were processed to test the effects of breed, gender, and their interaction.

${ }^{2}$ Normally distributed variables were analyzed using a mixed model to test the effects of breed, gender, and their interaction, and their data are expressed as $L$ smeans \pm SEM.

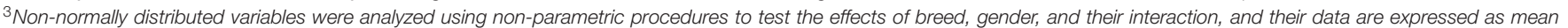
and $95 \%$ confidence intervals.

a,b Values within a row with different superscripts differ $\left({ }^{*} P<0.05\right)$.

ns, not significant.

non-normally distributed data such as the prevalence of rumens with star scar, lungs with severe pneumonia (Score 3), and livers with abscess and/or adherence.

To find out the possible redundancies between different parameters recorded at the abattoir, correlations among the prevalence of lesions detected on the same organ or on different organs were assessed at batch level (with a batch prevalence $\geq 1 \%$ ) using Spearman's rank correlation (PROC CORR of SAS 9.3; Institute Inc., Cary, NC).

Finally, quartiles of the batch prevalence of rumen, lung, and liver alterations (with a batch prevalence $\geq 1 \%$ ) were calculated as a benchmarking tool, according to what was proposed by Scollo et al. (3) in pigs. The third quartile (Q3) value was proposed as an alarm threshold for each lesion, and specific quartiles were calculated within breed or gender when there was a significant effect of these factors on a given lesion.

\section{RESULTS}

Results of this study regard 2,161 animals (1,376 bulls and 785 heifers) belonging to 153 batches ( 97 bulls and 56 heifers) that came from 80 different fattening units (from one to seven batches/farm). The observed batches had a mean size of 29.9 \pm 21.3 (SD) animals, and the average proportion of inspected animals per batch over the total number of animals within each batch was $65.5 \pm 28.8 \%$. Inspected cattle belonged to the following breeds: $\mathrm{CH}, 88$ batches; LIM, 28; and CR, 37 .

Almost 58 and $30 \%$ of the total inspected rumens showed hyperkeratosis or signs of ruminitis, respectively, and the prevalence of these lesions did not vary among breeds or genders (Table 2). Ulcers were detected only in $0.4 \%$ of the inspected rumens. The prevalence of rumens with star scars in the whole inspected sample was $15 \%$, and it was higher for bulls than heifers (Table 2).

The overall prevalence of rumens with Paramphistomum was $37 \%$, and it differed among breeds, being higher $(P<0.001)$ for $\mathrm{CH}(41.6 \pm 2.8 \%)$ and LIM $(39.4 \pm 4.8 \%)$ compared to CR $(21.3$ $\pm 3.8 \%)$. It was similar for bulls and heifer $(34.2 \pm 2.9 \%$ vs. 34.0 $\pm 3.6 \%$, respectively).

Regarding lung score distribution, the overall prevalence of lungs scored 1 (minimal pneumonia) reached almost $20 \%$ of the inspected animals. The overall prevalence of lungs scored 2 and 3 (moderate and severe pneumonia) was around $10 \%$ of the inspected animals. None of these prevalence rates differed for breed or gender effect (Table 2). Over the total inspected livers, those showing signs of lipidosis were very rare $(<0.5 \%)$ and those showing abscess and/or adherence were almost $4 \%$. No effects of breed or gender were found for the prevalence of liver alterations (Table 2).

Results of the Spearman rank correlations on lesion prevalence at the batch level are reported in Table 3. The prevalence of rumen mucosa with hyperkeratosis was significantly correlated $(P<0.001)$ to that of rumens with signs of ruminitis, and it was negatively correlated $(P<0.05)$ to the prevalence of lungs showing severe signs of pneumonia. A positive correlation $(P<0.001)$ was also found between the prevalence of rumens with signs of ruminitis and that of rumens with star scars (Table 3).

The quartiles of the prevalence of the specific lesions in the inspected batches are shown in Table 4. As the rumen hyperkeratosis was recorded with high frequency in most of 


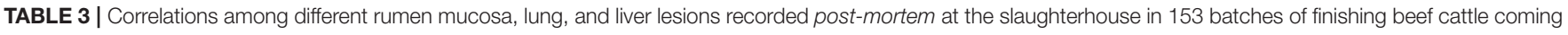
from 80 Italian commercial farms.

\begin{tabular}{|c|c|c|c|c|c|c|c|}
\hline \multirow[t]{2}{*}{ Specific disorder } & \multicolumn{3}{|c|}{ Rumen mucosa } & \multicolumn{3}{|c|}{ Lung } & \multirow{2}{*}{$\begin{array}{c}\text { Liver } \\
\text { Abscess } \\
\text { and/or } \\
\text { adherence }\end{array}$} \\
\hline & Hyperkeratosis & $\begin{array}{l}\text { Signs of } \\
\text { ruminitis }\end{array}$ & Star scar & $\begin{array}{c}\text { Minimal } \\
\text { pneumonia }\end{array}$ & $\begin{array}{c}\text { Moderate } \\
\text { pneumonia }\end{array}$ & $\begin{array}{c}\text { Severe } \\
\text { pneumonia }\end{array}$ & \\
\hline \multicolumn{8}{|l|}{ Rumen mucosa } \\
\hline \multirow[t]{2}{*}{ Hyperkeratosis } & & 0.284 & 0.054 & 0.130 & -0.091 & -0.170 & -0.006 \\
\hline & & 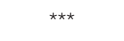 & ns & ns & ns & * & ns \\
\hline \multirow[t]{2}{*}{ Signs of ruminitis } & & & 0.439 & 0.004 & 0.038 & -0.076 & 0.047 \\
\hline & & & $* \star \star *$ & ns & ns & ns & ns \\
\hline \multirow[t]{2}{*}{ Star scar } & & & & 0.096 & -0.151 & -0.068 & -0.076 \\
\hline & & & & ns & ns & ns & ns \\
\hline \multicolumn{8}{|l|}{ Lung } \\
\hline \multirow{2}{*}{$\begin{array}{l}\text { Minimal } \\
\text { pneumonia }\end{array}$} & & & & & -0.185 & 0.130 & -0.099 \\
\hline & & & & & * & ns & ns \\
\hline \multirow{2}{*}{$\begin{array}{l}\text { Moderate } \\
\text { pneumonia }\end{array}$} & & & & & & 0.130 & -0.100 \\
\hline & & & & & & ns & ns \\
\hline \multirow[t]{2}{*}{ Severe pneumonia } & & & & & & & 0.062 \\
\hline & & & & & & & ns \\
\hline
\end{tabular}

Different symbols indicate significant correlations $\left({ }^{*} P<0.05\right.$ and $\left.{ }^{* \star *} P<0.001\right)$.

ns, not significant.

TABLE 4 | Statistical description with quartiles of the batch average prevalence of specific organ lesions recorded post-mortem at the slaughterhouse in 153 batches of finishing beef cattle coming from 80 Italian commercial farms.

\begin{tabular}{|c|c|c|c|}
\hline Specific lesion (\% of organs affected/batch) & Q1 & Median & Q3 \\
\hline \multicolumn{4}{|l|}{ Rumen mucosa } \\
\hline Hyperkeratosis & 40.0 & 60.0 & 75.0 \\
\hline \multicolumn{4}{|l|}{ Star scar } \\
\hline Bull & 0.0 & 12.5 & 26.7 \\
\hline \multicolumn{4}{|l|}{ Lung } \\
\hline Minimal pneumonia & 10.0 & 20.0 & 26.7 \\
\hline Moderate pneumonia & 0.0 & 6.7 & 13.3 \\
\hline Severe pneumonia & 0.0 & 6.7 & 13.3 \\
\hline \multicolumn{4}{|l|}{ Liver } \\
\hline Abscess and/or adherence & 0.0 & 0.0 & 6.7 \\
\hline
\end{tabular}

Q1, first quartile; Q3, third quartile.

the inspected batches, its median and Q3 values were very high, followed by the signs of ruminitis with a Q3 value of $47 \%$ (Figure 1). Batch prevalence of star scars differed between bulls and heifers, with the former having a higher alarm threshold value than the latter (27 vs. $16 \%$, respectively; Figure 2). The prevalence of minimal signs of pneumonia at the batch level was higher than those of moderate and severe signs of pneumonia, leading to different alarm threshold values (Figure 3). The presence of abscesses or adherence in the liver was quite limited, with an alarm threshold value around $7 \%$ (Figure 4).

\section{DISCUSSION}

The Italian beef cattle industry accounts for more than 1.5 million animals per year (5), nearly one third of the total beef cattle fattened in Europe. It is mainly located in the Po Valley, a fertile and homogeneous climatic area, and is based on the finishing of purebred or crossbred bulls and heifers imported from abroad at an age of 10-14 months and a live weight at the arrival of $300-400 \mathrm{~kg}$ (23). After their transfer to Italy, cattle are finished for about 7 months in specialized fattening units, housed in multiple pens with fully slatted or deep littered floor (24). 


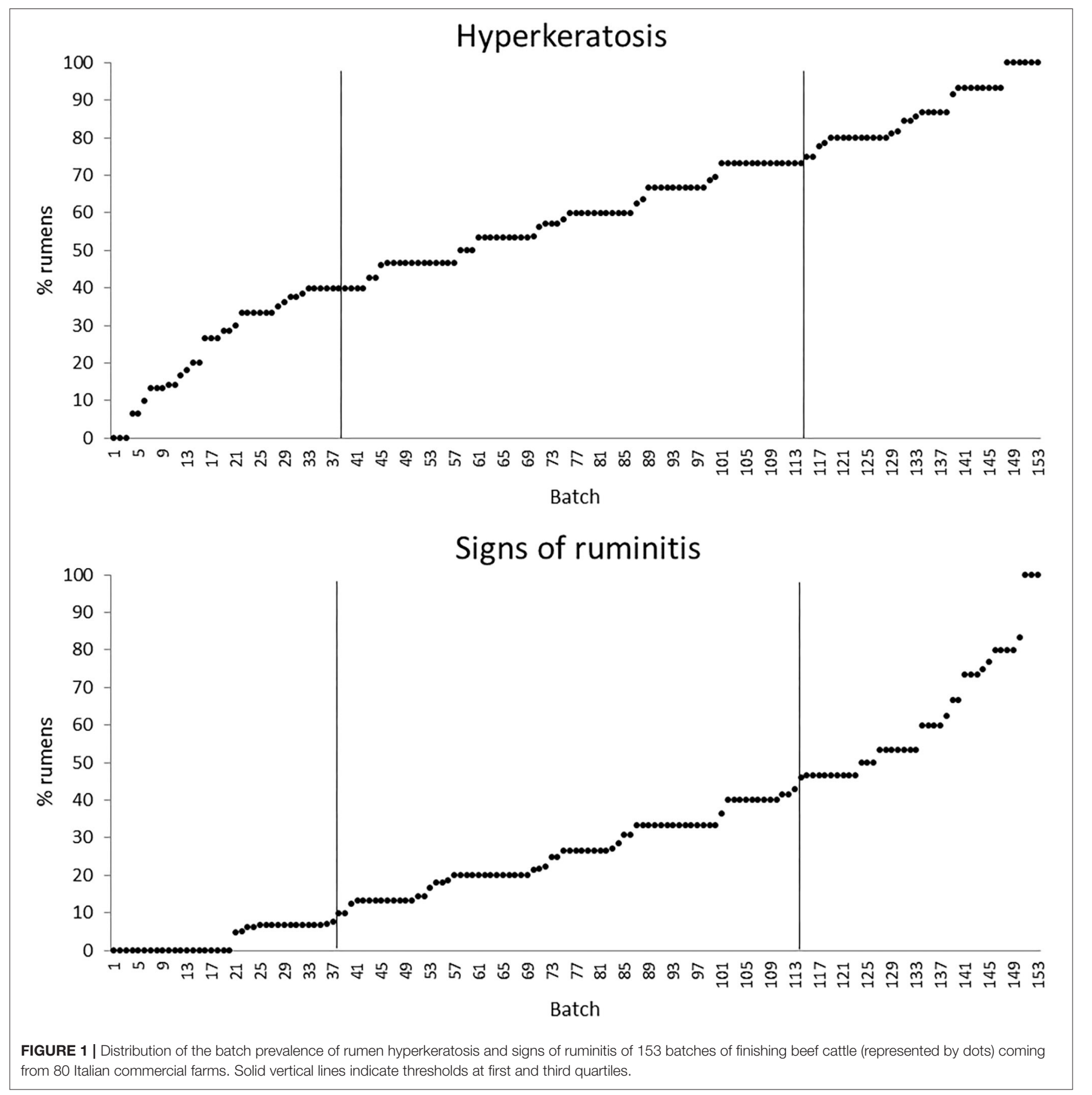

Beef farms operate according to a rather standardized feeding program made of high-starch diets based on maize silage to promote maximum daily gain (25). Both housing and feeding plans have been recognized as potential risk factors for the health and welfare of the animals $(1,11)$, with increased costs for medical treatments (26).

The prevalence of rumen mucosa hyperkeratosis found in this study was considerably high and so widespread among batches that might be interpreted as an adaptive response of the animals to some common challenging conditions. Indeed, this alteration of the rumen wall is mainly associated with the provision of highstarch/low-fiber diets during the finishing period (27). At rumen level, the starch load might cause a temporary imbalance between production and absorption of fatty acids with a consequent drop in ruminal $\mathrm{pH}(14,28)$. When a prolonged condition of low rumen $\mathrm{pH}$ (5.5-5.0) persists, bacteria might invade the rumen wall and eventually lead to ruminitis and severe damage to the rumen mucosa papillae $(14,29)$. The quite high prevalence of 


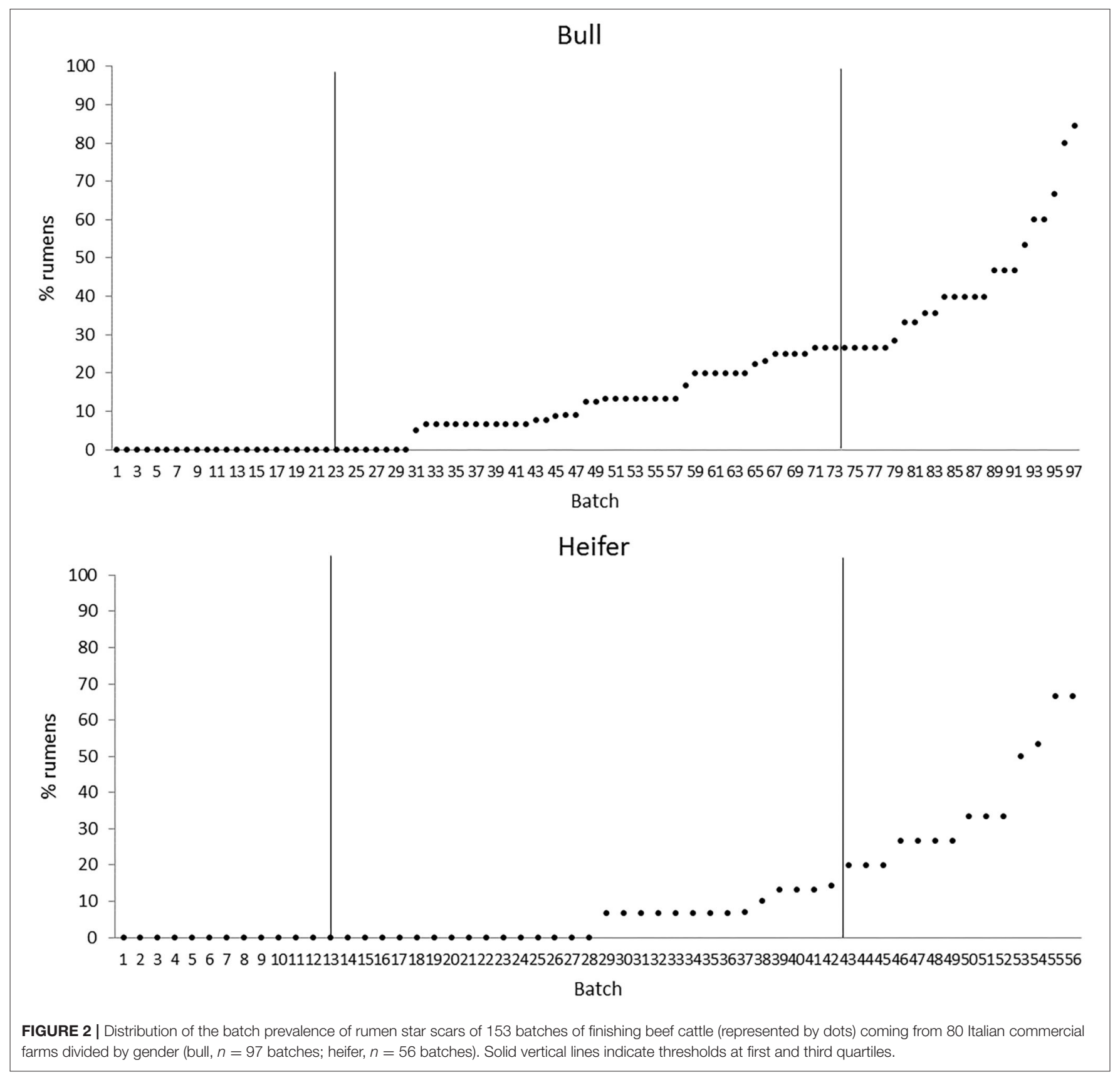

signs of ruminitis recorded in this study is consistent to this hypothesis. The relevant role of the dietary energy content in developing specific damage on the rumen wall has been proved by several studies on finishing feedlot cattle, where animals fed diets with more than $70 \%$ of concentrate in a finishing period of 3 months had an occurrence of rumen mucosa ulcers and/or ruminitis of $19.9-31.3 \%(1,26)$.

Particularly alarming in the current study was the noticeable prevalence of star scars on the rumen mucosa that was similar to the values recorded in feedlot cattle $(1,26)$. Star scars represent the footprint of a previous pathological condition, as they are outcomes of the healing process from ruminitis or ulceration.
Even their etiology arises from the ingestion of a high amount of grains or of high-starch/low-fiber rations that induce a relevant chemical insult to the ruminal mucosa with a reduction of its absorptive capacity $(1,2,30)$. In the present study, the prevalence of star scars was higher for bulls than for heifers, and this result may be attributed to the different feeding plans adopted for these two cattle categories. Indeed, beef heifers are fed more roughages and fattened for a shorter period than beef bulls to prevent an excessive carcass fatness score (23).

In this study, the occasional finding of massive rumen infestation by parasites of the genus Paramphistomum was heavily influenced by cattle breeds likely reflecting their different 

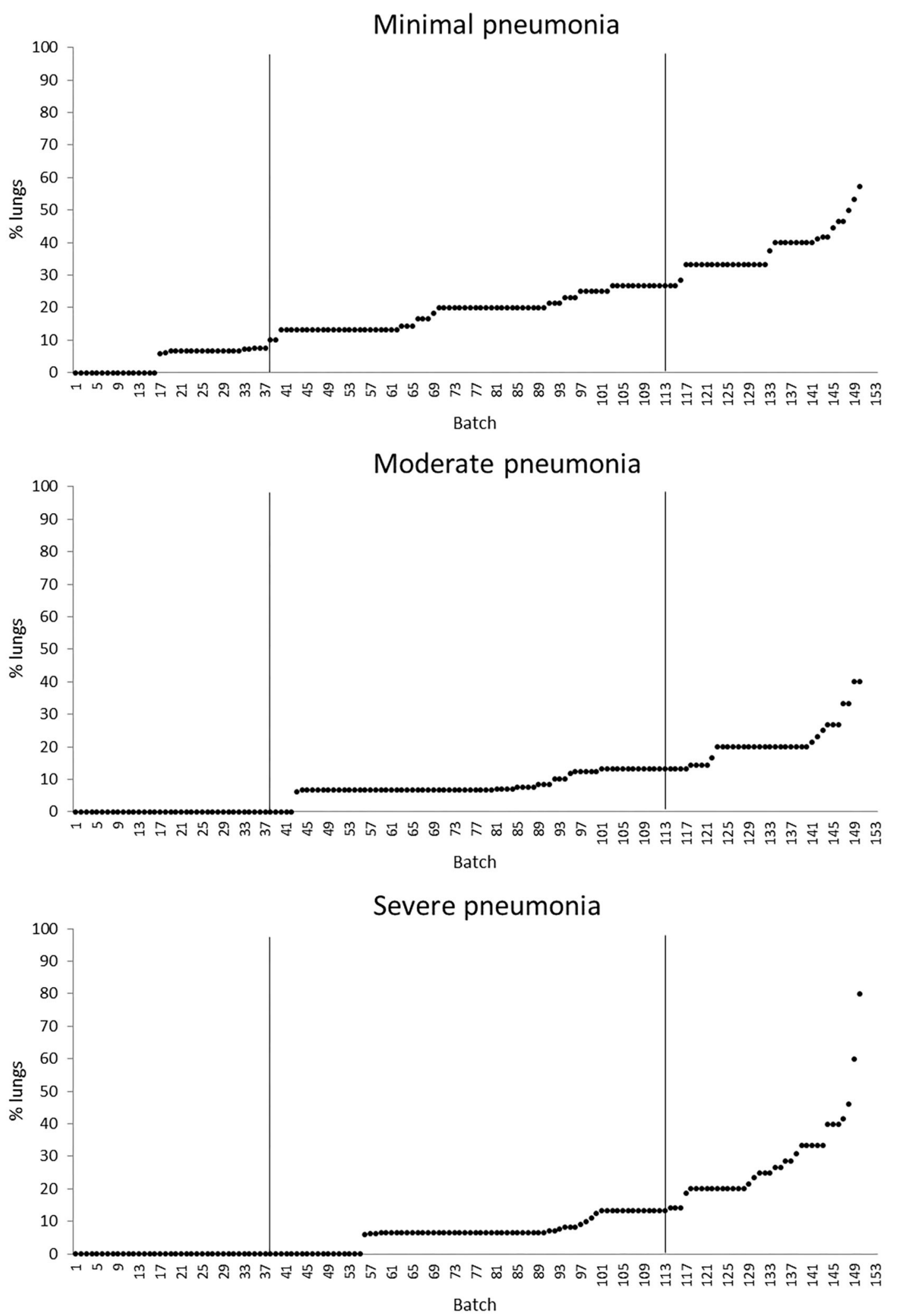

FIGURE 3 | Distribution of the batch prevalence of lung minimal, moderate, and severe pneumonia of 153 batches of finishing beef cattle (represented by dots) coming from 80 Italian commercial farms. Solid vertical lines indicate thresholds at first and third quartiles. 


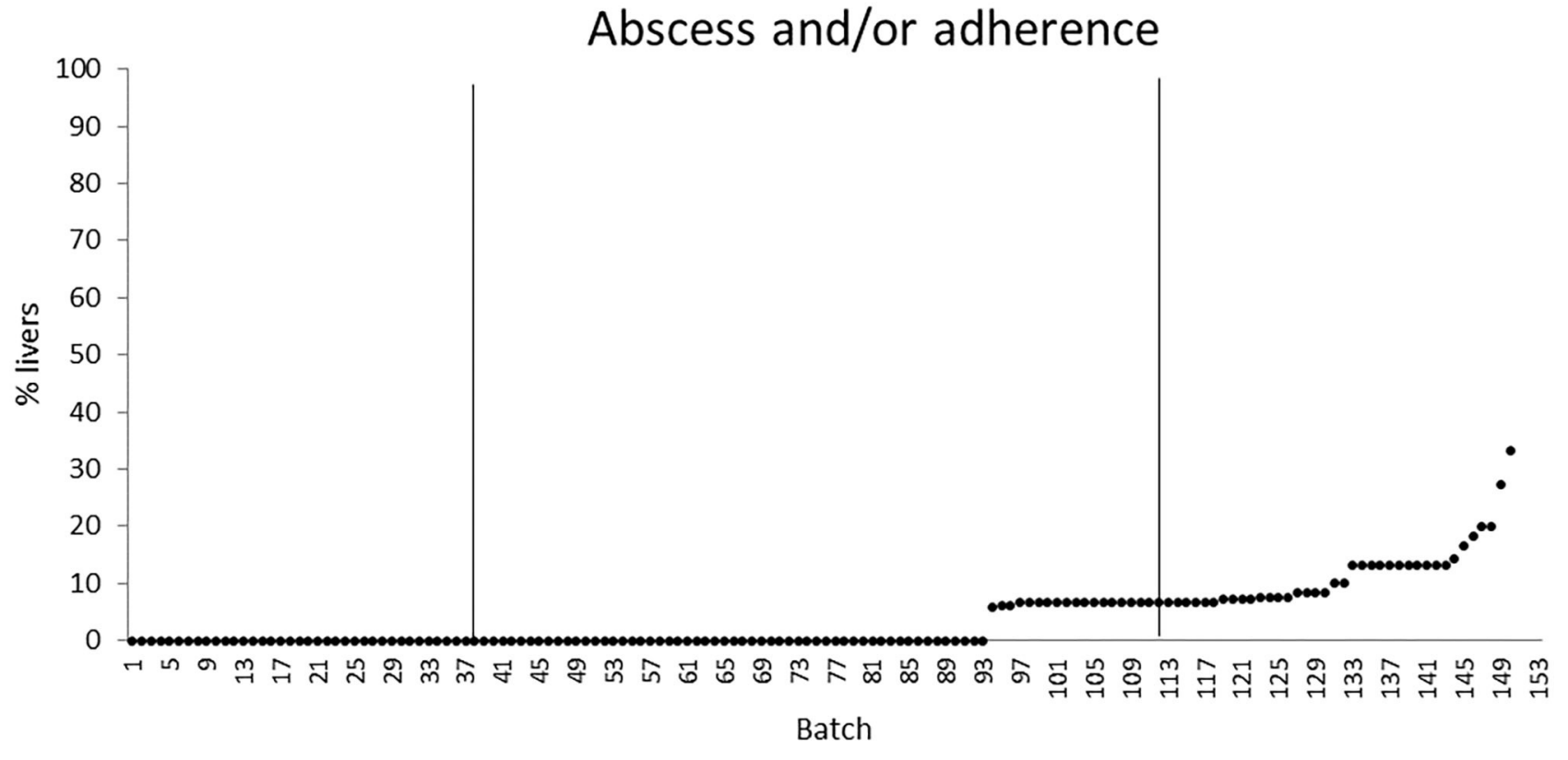

FIGURE 4 | Distribution of the batch prevalence of liver abscess and/or adherence of 153 batches of finishing beef cattle (represented by dots) coming from 80 Italian commercial farms. Solid vertical lines indicate thresholds at first and third quartiles.

origins. French $\mathrm{CH}$ and LIM are generally kept at pasture before the transfer to Italy and thus easily exposed to Paramphistomum infestation (31). Crossbred cattle are instead mainly of domestic origin, and they have a very limited or no access to pasture before finishing. Paramphistomum infestation usually has a subclinical course; however, the negative effect of a massive infestation on rumen health and absorptive efficiency should be carefully evaluated by further dedicated studies.

In literature, the reported prevalence of liver abscesses in feedlot cattle showed a great variability from $4.8 \%$ in McKeith et al. (32) to $13.9 \%$ in Garcia et al. (33), with the highest value of $32 \%$ reported by Nagaraja and Lechtenberg (34) for Canadian and North American cattle. The difference between these values and the prevalence recorded in the current study (about 4.0\%) was presumably due to the diverse feeding regimen and environmental conditions (indoor vs. outdoor housing, climatic zone, etc.) that characterize these beef production systems. Some feedlot studies have proven the existence of an association between the occurrence of rumen pathologies and liver abscesses within the so-called ruminitis-liver abscess complex $(1,12)$. In our study, the low prevalence of liver abscesses and the lack of any association between them and the rumen lesions suggest that a possible SARA condition affecting the inspected batches did not induce a severe inflammatory response with the translocation of bacteria and endotoxins across the ruminal epithelium.

The overall prevalence of healthy lungs recorded in this study (on average 62.0\%) was satisfactory if compared to the outcome $(36 \%)$ of a similar study carried out on intensively finished beef cattle reared in the same area (8). Moreover, our percentage of healthy lungs was consistent with previous values recorded at the slaughter for feedlot cattle, which ranged from 60 to $72 \%(1,10,35)$. In these feedlot studies, the prevalence of clinical signs of 35 and $8.17 \%$ observed in vivo by Wittum et al. (35) and Schneider et al. (10), respectively, was significantly lower than that of lung lesions recorded post-mortem, indicating that direct on-farm diagnosis could neglect a large number of animals that have likely suffered from subclinical pneumonia (10). Therefore, as the evaluation of lungs at the abattoir is a reliable indicator of the real occurrence of respiratory diseases during the fattening period, data from post-mortem inspections should complement the in vivo health checks in order to detect specific risks that could impair the lungs' health on farm.

The improvement of animal health surveillance through the identification of simple reliable indicators is a priority of the EU animal health strategy (36). In this regard, post-mortem inspections at the abattoir are an important complement to the intra vitam health checks, as the recorded lesions can be reflective of subclinical disease status not easily detected in the live animal. In addition, a benchmarking system based on inspections data about the prevalence and severity of lesions at batch level could support farm veterinarians to prioritize their actions to improve the herd management from a health and welfare perspective.

Consistent with the approach proposed by Scollo et al. (3) in pigs, the calculation of the quartiles for the batch population according to the prevalence of each rumen, lung, and liver lesion allows to allocate each inspected batch in a specific "health class." The rationale behind this benchmarking system should foresee a targeted intervention by the stockman and the veterinarian in those farms for which, at slaughter, 
batches of cattle showed a prevalence above the defined alarm threshold (Q3) for a given lesion. The implementation of the system through a wide collection of post-mortem organ inspection data in several abattoirs would set reliable alarm thresholds for each lesion for a specific country or production system. At this purpose, to limit a possible bias due to the interobserver variation, it would be advisable to organize a proper training to standardize the definitions of lesions and scores across the inspectors working in different abattoirs. A regular application of the benchmarking system should promote a virtuous cycle in which beef farms where a specific intervention is needed are taking actions to improve health and feeding management and move to a better quartile. In the medium to long run, the benchmarking system should support a general and continuous improvement of beef cattle health management, resulting in better performance and a lower use of pharmaceutical treatments.

This study provided an overview of the occurrence of some specific rumen, lung, and liver lesions that affect intensively finished beef cattle. Some of the recorded lesions, like rumen hyperkeratosis and signs of ruminitis, had a very high prevalence, suggesting the need for an intervention on the feeding management during the finishing period. Knowledge of post-mortem organ inspection data is of value, as several lesions can be reflective of subclinical disease status not easily detected in the live animal. The variability observed among the batch prevalence for specific signs of diseases suggested the development of a benchmarking system to help farm veterinarians to drive herd health improvement. A wide implementation of this system should promote a continuous improvement of beef cattle management from a health and welfare perspective.

\section{DATA AVAILABILITY STATEMENT}

The raw data supporting the conclusions of this article will be made available by the authors, without undue reservation.

\section{REFERENCES}

1. Rezac DJ, Thomson DU, Bartle SJ, Osterstock JB, Prouty FL, Reinhardt CD. Prevalence, severity, and relationships of lung lesions, liver abnormalities, and rumen health scores measured at slaughter in beef cattle. J Anim Sci. (2014) 92:2595-602. doi: 10.2527/jas.2013-7222

2. Rezac DJ, Thomson DU, Siemens MG, Prouty FL, Reinhardt CD, Bartle SJ. A survey of gross pathologic conditions in cull cows at slaughter in the Great Lakes region of the United States. J Dairy Sci. (2014) 97:74227-35. doi: $10.3168 /$ jds.2013-7636

3. Scollo A, Gottardo F, Contiero B, Mazzoni C, Leneveu P, Edwards SA. Benchmarking of pluck lesions at slaughter as a health monitoring tool for pigs slaughtered at $170 \mathrm{~kg}$ (heavy pigs). Prev Vet Med. (2017) 144:20-8. doi: 10.1016/j.prevetmed.2017. 05.007

4. Louton H, Erhard M, Wöhr AC. Acquisition of animal-based welfare measures at slaughter of poultry. Fleischwirtschaft. (2018) 98:94-8.

5. Cozzi G. Present situation and future challenges of beef cattle production in Italy and the role of the research. Ital J Anim Sci. (2007) 6:389-96. doi: 10.4081/ijas.2007.1s.389

\section{ETHICS STATEMENT}

Ethical review and approval was not required for the animal study because the organs' assessments were performed post-mortem only.

\section{AUTHOR CONTRIBUTIONS}

FG and GC conceived and designed study. LM, MB, IL, and PP collected, compiled, and analyzed the data. BC performed statistical analyses. LM, IL, and GC drafted and edited the manuscript. All authors contributed to the article and approved the submitted version.

\section{FUNDING}

This research was funded by the University of Padova within the PRAT project CPDA158107 entitled use of animal-based measures taken at the slaughterhouse as indicators of welfare at the farm: a retrospective approach.

\section{ACKNOWLEDGMENTS}

The authors wish to thank the AZOVE beef cattle producers' association and their veterinarians for their precious support and the official veterinary inspectors and all personnel of the slaughterhouses involved (Colomberotto S.p.a., Pellizzari Carni dei Fratelli Pellizzari S.n.c., and Macello Piemonte Nord S.r.l.) for hosting the research group for data collection.

\section{SUPPLEMENTARY MATERIAL}

The Supplementary Material for this article can be found online at: https://www.frontiersin.org/articles/10.3389/fvets. 2020.622837/full\#supplementary-material

6. Thompson PN, Stone A, Schultheiss WA. Use of treatment records and lung lesion scoring to estimate the effect of respiratory disease on growth during early and late finishing periods in South African feedlot cattle. J Anim Sci. (2006) 84:488-98. doi: 10.2527/2006.842488x

7. Buchanan JW, Mac Neil MD, Raymond RC, McClain AR, Van Eenennaam AL. Rapid Communication: Variance component estimates for Charolais-sired fed cattle and relative economic impact of bovine respiratory disease. J Anim Sci. (2016) 94:5456-60. doi: 10.2527/jas.2016-1001

8. Caucci C, Di Martino G, Schiavon E, Garbo A, Soranzo E, Tripepi L, et al. Impact of bovine respiratory disease on lung lesions, slaughter performance and antimicrobial usage in French beef cattle finished in North-Eastern Italy. Ital J Anim Sci. (2018) 17:1065-9. doi: 10.1080/1828051X.2018.14 26395

9. Edwards TA. Control methods for bovine respiratory disease for feedlot cattle. Vet Clin North Am Food Anim Pract. (2010) 26:273-84. doi: 10.1016/j.cvfa.2010.03.005

10. Schneider MJ, Tait Jr RG, Busby WD, Reecy JM. An evaluation of bovine respiratory disease complex in feedlot cattle: Impact on performance and carcass traits using treatment records and lung lesion scores. J Anim Sci. (2009) 87:1821-7. doi: 10.2527/jas.2008-1283 
11. Scientific Committee on Animal Health and Animal Welfare (SCAHAW). The Welfare of Cattle Kept for Beef Production. Sanco.C.2/AH/R22/2000 (2001). Retrieved from: http://ec.europa.eu/food/fs/sc/scah/out54_en.pdf (accessed September 03, 2020).

12. Attia NE. Subacute ruminal acidosis in feedlot: Incidence, clinical alterations and its sequelae. Adv Anim Vet Sci. (2016) 4:513-7. doi: 10.14737/journal.aavs/2016/4.10.513.517

13. Hernández J, Benedito JL, Abuelo A, Castillo C. Ruminal acidosis in feedlot: from aetiology to prevention. Sci World J. (2014) 2014:702572. doi: $10.1155 / 2014 / 702572$

14. Kleen JL, Hooijer GA, Rehage J, Noordhuizen JPTM. Subacute ruminal acidosis (SARA): a review. J Vet Med A Physiol Pathol Clin Med. (2003) 50:406-14. doi: 10.1046/j.1439-0442.2003. 00569.x

15. Khafipour E, Plaizier JC, Aikman PC, Krause DO. Population structure of rumen Escherichia coli associated with subacute ruminal acidosis (SARA) in dairy cattle. J Dairy Sci. (2011) 94:351-60. doi: 10.3168/jds.2010-3435

16. Khiaosa-ard R, Zebeli Q. Diet-induced inflammation: From gut to metabolic organs and the consequences for the health and longevity of ruminants. Res Vet Sci. (2018) 120:17-27. doi: 10.1016/j.rvsc.2018.08.005

17. Nagaraja TG, Titgemeyer EC. Ruminal acidosis in beef cattle: the current microbiological and nutritional outlook. J Dairy Sci. (2007) 90:E17-38. doi: $10.3168 /$ jds.2006-478

18. Gianesella M, Morgante M, Cannizzo C, Stefani A, Dalvit P, Messina V, et al. Subacute ruminal acidosis and evaluation of blood gas analysis in dairy cow. Vet Med Int. (2010) 2010:392371. doi: 10.4061/2010/3 92371

19. Hinders RG, Owen FG. Relation of ruminal parakeratosis development to volatile fatty acid absorption. J Dairy Sci. (1965) 48:1069-73. doi: 10.3168/jds.S0022-0302(65)88393-X

20. Thomson RG. Rumenitis in cattle. Can Vet J. (1967) 8:189-92.

21. Thompson PN, Schultheiss WA, Hentzen A. The Effect of Rumen Mucosal Lesions on Growth in South African Feedlot Cattle. Budapest: World Buiatrics Congress (2008). p. 12.

22. Leruste H, Brscic M, Heutinck LFM, Visser EK, Wolthuis-Fillerup $\mathrm{M}$, Bokkers EAM, et al. The relationship between clinical signs of respiratory system disorders and lung lesions at slaughter in veal calves. Prev Vet Med. (2012) 105:93-100. doi: 10.1016/j.prevetmed.2012. 01.015

23. Gallo L, De Marchi M, Bittante G. A survey on feedlot performance of purebred and crossbred European young bulls and heifers managed under intensive conditions in Veneto, northeast Italy. Ital J Anim Sci. (2014) 13:798807. doi: 10.4081 /ijas. 2014.3285

24. Magrin L, Gottardo F, Brscic M, Contiero B, Cozzi G. Health, behaviour and growth performance of Charolais and Limousin bulls fattened on different types of flooring. Animal. (2019) 13:2603-11. doi: 10.1017/S175173111900106X

25. Cozzi G, Mazzenga A, Contiero B, Burato G. The use of corn silage in beef cattle feeding during the finishing period. Ital J Anim Sci. (2008) 7:39-52. doi: $10.4081 /$ ijas.2008.39
26. Malafaia P, Granato TAL, Costa RM, de Souza VC, Costa DFA, Tokarnia $\mathrm{CH}$. Major health problems and their economic impact on beef cattle under two different feedlot systems in Brazil. Pesqui Vet Bras. (2016) 36:837-43. doi: $10.1590 / \mathrm{s} 0100-736 \times 2016000900008$

27. Meyer NF, Bryant TC. Diagnosis and management of rumen acidosis and bloat in feedlots. Vet Clin North Am Food Anim Pract. (2017) 33:481-98. doi: 10.1016/j.cvfa.2017.06.005

28. Plaizier JC, Khafiour E, Li S, Gozho GN, Krause DO. Subacute ruminal acidosis (SARA), endotoxins and health consequences. Anim Feed Sci Technol. (2012) 172:9-21. doi: 10.1016/j.anifeedsci.2011. 12.004

29. Wiese BI, Campbell J, Hendrick S, Penner GB. Ruminal pH, short-chain fatty acid concentrations, and serum acute phase protein concentrations during finishing for steers with and without rumen and liver pathology. Can J Anim Sci. (2017) 97:581-9. doi: 10.1139/CJAS-2016-0212

30. Blowey R, Weaver AD. Alimentary disorders. In: Color Atlas of Diseases and Disorders of Cattle. 3rd Ed. London: Elsevier Health Sciences (2011). p. 53-82. doi: 10.1016/B978-0-7234-3602-7.00010-8

31. Sanabria REF, Romero JR. Review and update of paramphistomosis. Helminthologia. (2008) 45:64-8. doi: 10.2478/s11687-008-0012-5

32. McKeith RO, Gray GD, Hale DS, Kerth CR, Griffi DB, Savell JW, et al. National beef quality audit - 2011: Harvest-floor assessments of targeted characteristics that impact quality and value of cattle, carcasses, and byproducts. J Anim Sci. (2012) 90:5135-42. doi: 10.2527/jas.2012-5477

33. Garcia LG, Nicholson KL, Hoffman TW, Lawrence TE, Hale DS, Griffi DB, et al. National beef quality Audit - 2005: survey of targeted cattle and carcass characteristics related to quality, quantity, and value of fed steers and heifers. J Anim Sci. (2008) 86:3533-43. doi: 10.2527/jas.2007-0782

34. Nagaraja TG, Lechtenberg KF. Liver abscesses in feedlot cattle. Vet Clin Food Anim. (2007) 23:351-69. doi: 10.1016/j.cvfa.2007.05.002

35. Wittum TE, Woollen NE, Perino LJ, Littledike ET. Relationships among treatment for respiratory tract disease, pulmonary lesions evident at slaughter and rate of weight gain in feedlot cattle. J Am Vet Med Assoc. (1996) 209:814-8.

36. European Commission. A New Animal Health Strategy for the European Union (2007-2013) Where Prevention is Better than Cure. European Commission Edn. Office for Official Publications of the European Communities. Luxemburg (2007). p. 1-26.

Conflict of Interest: The authors declare that the research was conducted in the absence of any commercial or financial relationships that could be construed as a potential conflict of interest.

Copyright (๐) 2021 Magrin, Brscic, Lora, Prevedello, Contiero, Cozzi and Gottardo. This is an open-access article distributed under the terms of the Creative Commons Attribution License (CC BY). The use, distribution or reproduction in other forums is permitted, provided the original author(s) and the copyright owner(s) are credited and that the original publication in this journal is cited, in accordance with accepted academic practice. No use, distribution or reproduction is permitted which does not comply with these terms. 